\title{
INSTRUMENTY SPÓJNOŚCI TEKSTU W DZIELE "LE LIVRE DES FAIS ET BONNES MEURS DU SAGE ROY CHARLES V" ŚREDNIOWIECZNEJ FRANCUSKIEJ PISARKI CHRISTINE DE PIZAN
}

\author{
MAŁGORZATA POSTURZYŃSKA-BOSKO \\ Uniwersytet Marii Curie-Skłodowskiej \\ margot.bosko@wp.pl
}

\begin{abstract}
Cohesion Instruments of the Text in the Work «Le livre des fais et bonnes meurs du sage roy Charles V » of a Medieval French Writer - Christine de Pizan
\end{abstract}

The article is an attempt of verification of the possibility and of its degree of the analysis of the linguistic tools that determine the text cohesion in political works of a medieval French writer Christine de Pizan (XV c). The cohesion relations depend on various linguistic as well as extralinguistic factors and diaphoric metaphors are one of ways to provide the textual cohesion in an economical manner. The concept of the textual economy is the outcome of linguistic and extralinguistic rules. In the world of the text based on a subjective perception, thematic progression is not always logical from the point of view of information orientation even more so because the compilation structure of the political work of Christine de Pizan opens the opportunities for emergence of unexpected cohesion relations.

Keywords: cohesion, diaphora, anaphora, cataphora Mots-clefs: cohésion, diaphore, anaphore, cataphore Słowa kluczowe: spójność, diafora, anafora, katafora 
Artykuł ten jest próbą odpowiedzi na pytanie, w jakim stopniu tekst jako całość determinuje funkcjonowanie narzędzi spójności. W dotychczasowych badaniach dotyczących spójności tekstu, językoznawcy raczej bazowali na przykładach skonstruowanych na potrzeby badań, bądź wyodrębnionych z tekstów autentycznych, ale bez analizy wpływu czynników kontekstowych na to zjawisko. Nasza analiza instrumentów spójności tekstu w dziele średniowiecznej pisarki Christine de Pizan (twórczość tej autorki przypada na koniec XIV i początek XV wieku) będzie próbą sprawdzenia, czy można za pomocą współczesnej metodologii określać zjawiska sprzyjające spójności w tekstach średniowiecznych, biorąc pod uwagę specyfikę języka średnio-francuskiego jak i strukturę tekstów. Narzędzia spójności, to wszelkie narzędzia językowe mające za cel utrzymać i zapewnić w sposób ekonomiczny spójność tekstu, a sprawdzają się najpełniej w tekście i dopiero ich analiza z punktu widzenia lektury globalnej, pozwala dostrzec ich rolę $\mathrm{w}$ procesie poznawczym tekstu. Jednakże analiza przykładów autentycznych niesie za sobą wiele problemów, ponieważ nie jest to tylko kwestia znalezienia i klasyfikacji odpowiedniego narzędzia spójności tekstu, ale wyeliminowania z otoczenia tekstu takich elementów, które uniemożliwiają prawidłową identyfikację owych narzędzi.

Zdajemy sobie bardzo dobrze sprawę z ryzyka, jakie niesie ze sobą taki projekt, ponieważ wyrażenia diaforyczne funkcjonujące w obrębie całego tekstu i stanowiące niejako jego element nieodzowny, są o wiele trudniejsze do analizy. I w tej kwestii całkowicie zgadzamy się z Georges'em Kleiberem [2001: 5], który mówi o ryzyku, jakie pociąga za sobą analiza tekstu jako całości pod kątem elementów spójności tekstu, ponieważ konfrontacja z większością z nich może prowadzić do niejednoznacznych efektów, które zależą od wielu czynników. Kleiber mówi o nadmiarze informacji kontekstowej nie zawsze dającej się okiełznać (une surabondance informative contextuelle pas toujours dominée [Kleiber 2001: 5]) w przykładach autentycznych i o niebezpieczeństwie niewłaściwej interpretacji relacji spójnościowych spowodowanej elementami tekstowymi i pozatekstowymi.

Obserwacja referencji, jako zjawiska występującego w relacjach spójnościowych tekstu oraz instrumentów spójność tę gwarantujących, to zagadnienie bardzo istotne z punktu widzenia aktualnych badań językoznawczych (zob. prace takich badaczy jak Georges Kleiber, Michel Charolles, Denis Apothéloz, Marek Kęsik), a ich analiza w tekstach średniowiecznych pozwoli, mamy nadzieję, stwierdzić, czy możliwe jest otrzymanie takich samych rezultatów dotyczących typologii, zarówno w języku średnio-francuskim, jak i współczesnym francuskim. Zasada ekonomii 
sprawdza się w każdym tekście, bez względu na epokę, różne są tylko środki jej osiągnięcia i to należałoby zbadać w tekście. Diafora jest jednym z głównych czynników warunkujących powstanie tekstu wewnętrznie spójnego i zadanie to realizuje na wiele różnych sposobów. Kryterium wektora dzieli diaforę na anaforę, kataforę i ana-kataforę, a istniejąca współzależność między tymi zjawiskami a kontekstem warunkuje powstanie koherentnego tekstu. Jak można zaobserwować, w świecie tekstu opierającym się na postrzeganiu subiektywnym, progresja tematyczna nie zawsze jest logiczna z punktu widzenia orientacji informacji, ponieważ zdarza się, że konstrukcje na pozór prezentujące dany typ diafory, nie są diaforyczne z punktu widzenia tekstu, bo nawiązują do informacji przedstawionej wcześniej w tekście, ale której ciągłość informacyjna nie została zapewniona przez np. inne środki spójności.

Kompilacyjna struktura dzieł Christine de Pizan, niezwykle interesująca w procesie wyszukiwania konektorów spójności tekstu, tworzy odrębny świat wewnątrz świata tekstu umożliwiający wystąpienie diafor, które nie są semantycznie powiązane z ciągami anaforycznymi wątków głównych. Dodatkową trudność stanowi podział dzieł na krótkie rozdziały, których tytuł zapowiada „zawartość”.

Rozpoznanie budowy tekstu było pierwszym krokiem w wyborze metodologii poszukiwania diafor. Obserwacje zostały zawężone do dzieła Le livre des fais et bonnes meurs $d u$ sage roy Charles $V$, którego spójność, z racji jego budowy, stanowi ciekawe zjawisko. Analiza diafor w tekście ma tę zaletę, że uruchamia, obok czynników strukturalnych, wszystkie aspekty psycho-językowe, co przekracza ramy zwykłej analizy językoznawczej.

Trudno byłoby znaleźć reguły uniwersalne dla każdego typu tekstu, dlatego więc wydawało się nam słuszne zdefiniować kilka reguł ogólnych, które trzeba brać pod uwagę przy analizie diafor w tekście, jednakże za każdym razem muszą one być przystosowane do specyfiki tekstu i stylu autora. W przypadku tekstów Christine de Pizan, konieczne było uzupełnienie kryteriów „wspólnych”, takich jak: odległość między antecedensem i wyrażeniem anaforycznym, nakładanie się odniesień pozatekstowych, obecność innych diafor, kryteriami, które wydają się szczególnie odpowiednie dla specyfiki dzieł Christine de Pizan, jej stylu i sposobu konstruowania wypowiedzi.

Analizę narzędzi spójności należy zacząć od krótkiego wyjaśnienia terminu diafora wprowadzonego przez Michela Maillarda [1974: 59], a zdefiniowanego, jako wyrażenie odnoszące się do danego obszaru tekstu (espace textuel) i zależne od kontekstu. Tekst jest jednostką semantyczną, której elementy powiązane są 
ze sobą przez eksplicytne związki spójnościowe. Zatem związki spójnościowe są relacjami semantycznymi między jednym elementem w tekście a drugim, którego istnienie jest niezbędne $w$ interpretacji pierwszego elementu.

Termin diafora nie określa kierunku relacji między elementem nazywanym referens (référant) - segment, który istnieje w zależności od elementu nazywanego antecedensem (antécédent); Maillard nazywa anaforą relację, kiedy antecedens poprzedza referens, a kataforą - kiedy wyrażenie wskazujące poprzedza w tekście źródło tego wyrażenia; diafora łączy te dwa terminy i oznacza generalnie referencję kontekstualną.

W zależności od wektora - kierunku relacji, istnieją anafory i katafory oraz ana-katafory; w zależności od natury formalnej diafory dzielimy na morfematyczne i leksematyczne. Identyfikacja typu referensa stanowi przyczynek do podziału diafor na kognitywne i metajęzykowe; z kolei, jeśli bierzemy pod uwage wielkość kontekstu, tzn. jak duży fragment antecedensa chcemy zreasumować referensem - mówimy o diaforze segmentalnej i rezomptywnej, również odległość między antecedensem i referensem wpływa na typologię diafory i, biorąc pod uwagę ten czynnik, dzielimy diafory na międzyzdaniowe i wewnątrzzdaniowe. Trudno byłoby przedstawić całą problematykę instrumentów spójności tekstu w jednym artykule, zostały tu więc nakreślone jedynie pewne ramy, w których postaramy się dokonać analizy diafor w dziele Christine de Pizan.

Trzymając się typologii przedstawionej powyżej, najpierw należałoby skupić się na analizie anafory $\mathrm{w}$ dziele Christine de Pizan. Relacja anaforyczna istnieje pomiędzy dwiema jednostkami A i B, kiedy interpretacja jednostki B zależy ściśle od istnienia jednostki A, do tego stopnia, że należy uznać, że jednostka B może być zinterpretowana tylko wtedy, kiedy powtarza w tekście częściowo lub całościowo jednostkę [Milner 1982: 18]. By zilustrować taką zależność, posłużymy się przykładem ze współczesnego języka francuskiego:

\section{(1) Paul est parti. Il a oublié son parapluie.}

kiedy identyfikacja zaimka il możliwa jest dzięki istnieniu antecedensa Paul.

Ten typ anafory morfematycznej występuje we współczesnym francuskim bardzo często, co uwarunkowane jest systemem gramatycznym języka, ponieważ osobowe formy czasownikowe wymagają użycia zaimków, przede wszystkim w celu identyfikacji osoby mówiącej (porównajmy język polski lub hiszpański, gdzie użycie zaimka osobowego nie jest konieczne: w przypadku użycia słowa mówię - osobę identyfikujemy poprzez formę czasownika, pisaną i mówioną). Obserwacja tekstów Christine prowadzi do następujących wniosków: w Le livre des 
fais et bonnes meurs, obok konstrukcji, gdzie występują zaimki trzeciej osoby il, elle i ich formy w liczbie mnogiej ils, elles przed formami czasowników, często zdarzają się fragmenty, w których występują formy czasownikowe bez podmiotu, $\mathrm{w}$ formie syntagmy nominalnej czy zaimka osobowego czasem na przestrzeni kilku linijek tekstu. I taka konstrukcja odpowiada dzisiejszemu użyciu zaimka osobowego w roli anafory morfematycznej. Obecność zaimka przy formie czasownika nie była rygorystycznie wymagana, zważywszy na brak normatywizmu, zwłaszcza w kwestii zasad gramatycznych i ortograficznych, jednakże lektura fragmentu (przykład 2) nie powoduje wahania co do interpretacji antecedensa jest nim bez wątpienia król Charles V i wszystkie formy poprzedzone zaimkiem il odnoszą się do syntagmy król, a formy osobowe czasownika bez zaimka: avisoit, volt, peust tym bardziej można odnieść do syntagmy król na zasadzie relacji antecedens - król i referens implicytny (domyślny) zaimek il - on.

(2) De la prudence du roy Charles, comme il fust perfait ameur de ses subgiez, avisoit en toutes manieres de les tenir en amour et dilection vers lui, pour ce voult vers eulx tenir tel maniere que de touz estas se tenissent pour contens des ordenances, qui estoient necessaires et convenables à faire en la gouvernance des fais du royaume; et, pour ce, non obstant que de sa seigneurie et autorité peust faire et ordoner de tout à son bon plaisir, quant venoit à conseiller sus l'estat du royaume, il appelloit à son conseil les bourgeois de ses bonnes villes, (...) afin qu'il moustrast la fiance qu'il avoit en eulx (...). [LFBM III: 28]

Z kolei częstym zabiegiem stylistycznym u Christine jest powtarzanie zmodyfikowanej syntagmy jak w przykładzie następującym: clerc de Bretagne - ce maistre - celui maistre:

(3) Ou temps Charles le Grant, vint un moult grant clerc de Bretagne, qui avoit nom Alcun ou Aubin ; de ce maistre aprist le roy toutes les ars liberaulx. Celui maistre, pour la grand amour, qu'il vid que Charles avoit à science, et par la priere qu'il lui en fist, tant pourchaça par son sens que il amena et fist translater les estudes des sciences de Romme à Paris (...). [LFBM I: 47]

Niestety, Christine nie zawsze dokładnie określa podmiot wypowiedzi, jak to ma miejsce w omawianym przykładzie; nagromadzenie zaimków il lekko zaburza wrażenie spójności, ponieważ identyfikacja antecedensa dla referensa il nie odbywa się automatycznie, jak to było w przykładzie poprzednim; rzeczywiście trzeba się zastanowić, kto wykonuje daną czynność w tym fragmencie tekstu i identyfikujemy sprawcę czynności: que il amena et fist translater les estudes des 
sciences de Romme à Paris raczej przez pryzmat kontekstu pozajęzykowego, a mianowicie faktu historycznego, iż to mistrz Alkuin, uważany za ojca chrzestnego renesansu karolińskiego, kazał sprowadzić i przetłumaczyć dzieła rzymskich autorów. Taką sytuację, gdy identyfikacja referensa nie jest automatyczna, a odnalezienie go w tekście odbywa się poprzez ustalenie relacji pomiędzy tymi dwoma elementami anafory, językoznawcy określają mianem anafory kognitywnej [Kęsik 1989: 42-47], kilkakrotne użycie zaimka il osłabia siłę referencyjną referensa i konieczna wydaje się jego zamiana na silniejszy leksem substytucyjny.

Warto podkreślić dużą częstotliwość występowania u Christine innych anafor morfematycznych, gdzie zaimki w funkcji dopełnień bliższych lub dalszych stanowią referens; większość konstrukcji anaforycznych tego typu to konstrukcje interfrastyczne, a dystans pomiędzy antecedensem, jak ma to miejsce w następnym przykładzie (4), son enferme ('chory') i referensem w postaci zaimka w funkcji dopełnienia dalszego lui ('jemu'), jak i drugim referensem, tym razem zaimka $\mathrm{w}$ funkcji dopełnienia bliższego le ('go') wynosi odpowiednio dla pierwszego referensa - jedno zdanie w obrębie zdania złożonego, a dla drugiego - dystans ów rozszerza się do dwóch zdań z obrębie zdania złożonego':

(4) (...) comme le bon medecin, qui desire la garison de son enferme, et ne laisse pour nulle pitié du goust estrange qu'il ne lui apreste et baille medecines, soient ameres ou doulces, qui ramener le pevent à vrai santé (...). [LFBM I: 28-29]

Dość charakterystycznym dla Christine sposobem konstruowania wypowiedzi z użyciem anafor morfematycznych jest dość duża odległość między antecedensem i referensem, wynosząca nawet kilka linijek tekstu, jak w przykładzie (5):

\footnotetext{
${ }^{1}$ Mówiąc o zdaniu w języku średnio-francuskim, trzeba zdawać sobie sprawę z faktu, iż interpunkcja średniowieczna nie wyodrębnia zdań sensu stricto, zatem termin zdanie nie wydaje się odpowiednie $\mathrm{w}$ odniesieniu do takich konstrukcji, należy raczej posłużyć się terminem wypowiedzenie (fr. proposition), a w przypadku konstrukcji złożonych - ciagami wypowiedzeń (fr. chaînes de propositions). Według Pierre'a Demarolle [1986: 47-48], jesteśmy przyzwyczajeni sądzić, że tekst zbudowany jest ze zdań, ale język średniowieczny cechuje się dużą niestabilnością interpunkcji i jeśli chodzi o formalne wyznaczenie zdania (w rozumieniu dzisiejszym), żadne formalne wyznaczniki nie odpowiadają w sposób systematyczny współczesnej interpunkcji. Jego zdaniem, próby wprowadzenia współczesnej interpunkcji w celu organizacji wyodrębnionych syntagm często wprowadzają nieścisłości, czy wręcz konstrukcje nie do zaakceptowania. Christiane Marchello-Nizia i Monique Lemieux [1997: 551] proponują również, by, analizując teksty średniowieczne, spojrzeć na nie z perspektywy językoznawstwa tekstu zamiast ograniczać się do zdania w rozumieniu współczesnym.
} 
(5) (...) le sage roy anobli de nature par longue genealogie continuée en triomphe, avec ce Dieu par grace doué de noblece de courage, laquelle lui fist delaissier ignorance en jeune aage, par vertu née d'admonnestement de grant discrecion, jugiant et cognoiscent les folz delis estre prejudiciables, damnables hors ordre de faame deue à dignité et trosne royal, desirant delaissier les choses basses et tendre aux hautes beatitudes, porpensa comment et par quel maniere on pourroit attraire et aluchier meurs vertueux par continuacion de vie salutaire, par quoy l'odeur de renommée devant Dieu et au monde lui fust permanable (...). [LFBM I: 36-37]

Jednakże, nawet tak duży dystans pomiędzy syntagmą le sage roy i zaimkami odnoszącymi się do niej nie sprawia trudności w identyfikacji antecedensa. Wynika to po części ze specyfiki budowy tekstu, ciągłości semantycznej i syntaktycznej wątku o królu Karolu V; analizowany fragment w całości odnosi się do osoby króla, zatem nawet duża odległość między antecedensem i referensem nie utrudnia ich identyfikacji. Anafory morfematyczne, inaczej nazywane pronominalnymi, powtarzają słowo lub syntagmę za pomocą zaimka i stanowią najbardziej liczną grupe wśród powtórzeń anaforycznych w tekstach Christine. Ciekawy przypadek stanowi zaimek przysłówkowy en; zastępuje on zarówno syntagmę - w takiej sytuacji mówimy o anaforze segmentalnej, jak i całe wypowiedzenie - tu z kolei mamy do czynienia $\mathrm{z}$ anaforą morfematyczną rezomptywną. Oba typy konstrukcji występują w tekstach Christine, jednakże można zaobserwować pewną dysproporcję w użyciu segmentalnym i rezomptywnym zaimka en: obok nielicznych przykładów powtórzenia przez zaimek en całego wypowiedzenia, jak w przykładzie (6):

(6) (...) le roy, qui desira le vray de la chose attaindre (...) chargia un de ses clers, soubtil homme, que il par bonne maniere se tirast devers cellui, qui devoit les diz .c. frans, et de loings feist semblant que moult desirast savoir faire le dit azur, et promeist .II. frans à cellui, et hardiment, pour plus grande decepvance, lui en baillast gage, mais que la ditte science lui voulsist apprendre, et ainsi fu fait ; pour laquelle promesse, pour cause du gage, s'y fia, et par tel convent lui promist enseigner à faire le dit azur que il ne le diroit au roy, ne à aultre, et la chose tendroit secrete ; et encore dist à l'autre que c'estoit moult belle science et bel secret; encore lui confessa que pour riens ne vouldroit qu'il ne le sceut faire. Cellui, qui plus n'en voulait savoir, au roy raporta ce que trouvé avoit (...). [LFBM I: 63]

użycie segmentalne tego zaimka jest zjawiskiem częstszym. Przykład (7) jest jednym z kilkunastu znalezionych na przestrzeni ok. 400 stron tekstu:

(7) (...) comme Aristipus fust retenus du conseil du roy de Cesile, Dyogenes n'en voult ester, combine que il en fust requis. [LFBM I: 65] 
gdzie zaimek en powtórzony dwa razy odnosi się do syntagmy conseil du roy de Cesile. Z kolei, przykład (8):

(8) (...) Comme le roy oist ceste chose n'en feist grant conte (...) [LFBM I: 51]

sugerowałby powtórzenie syntagmy ceste chose, zatem można by sklasyfikować tę relację między antecedensem i referensem jako segmentalną. Niestety, kontekst wyklucza anaforę segmentalną, ponieważ i syntagma ceste chose i zaimek en powtarzają, reasumują sytuację opowiedzianą kilka linijek wcześniej, w której król dowiaduje się o oblężeniu przez Anglików fortecy Guyenne i o dużym prawdopodobieństwie poddania tej twierdzy. Zatem jest to podwójne użycie referensa rezomptywne, co potwierdza złożoność relacji semantyczno-strukturalnej między elementami referencji.

W przeciwieństwie do zaimka en, zaimek przysłówkowy y pojawia się często $\mathrm{w}$ konstrukcjach anafory zarówno rezomptywnej jak i segmentalnej. W przykładzie (9), anafora rezomptywna y odnosi się do opisu przyjmowania gości przez króla, a antecedens w tym przypadku to ciąg wypowiedzeń, będący opisem na przestrzeni ok. 20 linijek tekstu wyglądu stołu, nakryć, ubioru, celebrowania posiłków:

(9) (...) ce roy (...) bien sçavoit recepvoir grans, moyens et petitz, et convenoit, quant les nobles princes venoient ainsi vers lui ou leurs messages, dinassent avec lui, et selon qu'ilz estoient notables, seoient à sa table ; et à ses disners, quant haulx princes y estoient, et meisment aux festes solemnelz, l'assiette des tables, l'ordenance les nobles paremens d'or et de soye ouvrez de haulte lice, qui tendus estoient par cesparois et ces riches chambers, de veloux brodées de grosses perles, d'or et de soye, de plusieurs estranges devices, les aournemens de partout, ces draps d'or tendus, pavillons et cielx sus ces haulz dois et chaieres cortinés, la vaisselle d'or et d'argent grant et pesant de toutes façons, en quoy l'en estoit servi par ces tables, les grans dreçoieurs couvers de flacons d'or, coupe et goubelles et autre vaiselle d'or à pierrerie, ses beaulz mez et entremez, vis, viandes delicieuses à grant largece, et cort planiere, à toutes gens certes pontifical chose estoit à veoir,et tant $\mathbf{y}$ estoit l'ordenance belle que, nonobstant y eust grant quantité de gent, si y estoit remedia que la presse n'y nuisoit (...). [LFBM III: 86-87]

W samym przykładzie zaimek y powtarza syntagmę à ses disners stanowiąc przykład anafory segmentalnej: (...) et à ses disners, quant haulx princes $y$ estoient (...) [LFBM I: 86]. 
Kolejną grupę wyrażeń anaforycznych, stanowią zaimki wskazujące rodzaju nijakiego, a ich użycie w tekście Christine przede wszystkim ilustruje zjawisko rezomptywne referencji; realizuje się ono za pomocą ça i cela. Zaimki te we współczesnym języku francuskim są prawie zawsze rezomptywne, jak twierdzi Maillard [1974: 59], stanowią wyrażenie anaforyczne, odnoszące się do kontekstu. Maillard przedstawia podział zaimków wskazujących na substytuty zmienne (celui-ci, celle-là) i substytuty niezależne od rodzaju i liczby antecedensa (ce, ceci, cela, ça); substytuty zmienne są zawsze segmentalne, a niezależne od rodzaju i liczby są zazwyczaj rezomptywne. Lektura tekstu Christine zdaje się potwierdzać użycie rezomptywne zaimka ce:

(10) De science, laquelle, comme dit Aristote, si que est dit devant, est habit des conclusions par les causes plus basses, qui est proprement à dire, sçavoir les causes des choses, pour quoy sont faictes et à quoy elles servent, et de ce sera parlé après. [LFBM I: 16]

W przykładzie (10), de ce sera parlé stanowi część anafory rezomptywnej, dzięki komentarzowi autorki (w tym fragmencie, identyfikacja antecedensa i referensa dzieje się na dwóch poziomach tekstu: narracji, będącej opowieścią o zasługach króla Karola V i we wtrętach, komentarzach autorki, zapowiadających kolejne opowieści o poczynaniach króla). Przykład (11) jest interesujący z innych powodów: mamy tu do czynienia z anaforą segmentalną à ce propos, w której antecedensem jest sapience, ale ten fragment zawiera wiele elementów spójności tekstu wartych zanalizowania.

(11) Et de theologie souvent vouloit ouir, entendoit les points de la science, en savoit parler, sentoit par raison et estude ce que theologie demoustre, laquelle chose est sapience; et, à ce propos dirons ce que Aristote en sa Methaphisique et autre part desclaire. [LFBM I: 13-14]

Zaimek en powtarza theologie, i jest to przykład diafory morfematycznej segmentalnej; ce que w stosunku do wypowiedzenia laquelle chose est sapience stanowi kataforę - relację o odwrotnym do anafory kierunku, gdzie referens odnosi się do kontekstu następującego, a nie uprzedniego, jak to działo się w przypadku anafory. Bez tego kontekstu, interpretacja referensa byłaby niemożliwa. Kolejną diaforę stanowi wypowiedzenie à ce propos dirons ce que Aristote (...) desclaire sus ceste matiere. Konstrukcja ce que Aristote odnosi się do kontekstu, pojawiającego się później w tekście, gdzie autorka przedstawia pokrótce definicję wiedzy (owej sapience), i jest kataforą rezomptywną międzyzdaniową. Kęsik [1989: 126-130] 
w swoim dziele La cataphore, pisząc o użyciu zaimka nijakiego ce w konstrukcjach kataforycznych, twierdzi, że może on występować zarówno w konstrukcjach kataforycznych wewnątrzzdaniowych jak i międzyzdaniowych, segmentalnych i rezomptywnych. Katafora jest o wiele mniej częstym zjawiskiem referencji tekstowej i w porównaniu z anaforą o wiele rzadziej występuje we współczesnym języku francuskim; w tekście Christine też stanowi zjawisko akcydentalne. W analizowanym tekście nie widać znaczących dysproporcji w użyciu zaimka ce w konstrukcjach kataforycznych jednego jak i drugiego typu. Niezmiernie ciekawą relacją spójnościową jest pewien zabieg stylistyczny używany przez autorkę regularnie, mianowicie rozpoczynanie każdego rozdziału dzieła, którego objętość wynosi od półtorej strony tekstu do czterech stron maksymalnie, od słów cy dit, cy preuve, cy parle, (z olbrzymią przewagą cy dit) np. XII Cy dit comment le roy Charles amoit livres, [et des belles translaciones, qu'il fist faire], XV Cy dit comment le roy Charles respondi amodereement à ceulz qui le hastoient, XXXVIII Cy dit comment le roy Charles receupt au Palais l'Empereur). Forma cy, będąca formą słabą (atone) wyrażenia deiktycznego ici (tu), wprowadza czytelnika w tematykę danego rozdziału. Jest to zjawisko bliskie wyrażeniu diaforycznemu, jednakże mamy tu do czynienia z użyciem symbolicznym zaimka wskazującego (emploi symbolique du démonstratif), gdzie wyrażenie indeksykalne (wskazujące) stanowi część źródła swojego referensa i jest szczególnym przypadkiem pomiędzy deixis tekstualną a wyrażeniem diaforycznym².

Ta dość zwięzła analiza funkcjonowania relacji spójnościowych w dziele Christine de Pizan prowadzi do wniosku, że zastosowanie współczesnych kryteriów diafory w tekstach musi być poprzedzone analizą kontekstu. Nasze obserwacje nie rozwiązują definitywnie tej kwestii, sygnalizują raczej konieczność traktowania tekstu jako pewnej jedności, w której zachodzą wszelkiego typu relacje spójnościowe, zależne od siebie i od czynników pozatekstowych, pozwalające dostrzec szerokie spektrum spójności tekstu. Badanie spójności wymaga odpowiedniego instrumentarium do analizy właściwego antecendensa, którego identyfikacja zależy od kontekstu, zawierającego informacje pozwalające wybrać pomiędzy dwoma możliwościami, budowy tekstu analizowanego i właściwości języka średnio-francuskiego, zarówno gramatycznych jak i semantycznych.

\footnotetext{
2 Patrz Fillmore C.J., 1971, Lectures on Deixis, CSLI Publications (reed. 1997).
} 


\section{Bibliografia}

\section{Źródła}

LFBM: Le Livre des fais et bonnes meurs du sage Roy Charles V, 2 volumes, éd. Suzanne Solente, Paris 1936-1940: Champion (SHF).

\section{Opracowania:}

APOTHELOZ D., 1995: Rôle et fonctionnement de l'anaphore dans la dynamique textuelle, Génève: Librairie Droz.

CHAROlles M., 1990: L'anaphore associative. Problèmes de délimitation, „Verbum", XIII, t. 3, s. 119-148.

CHAROLLES M., 1992: La veuve ou l'orphelin ou : comment les îlots anaphoriques refont surface, w: Lexique et inférence(s), éd. J.E. Tyvaert, Paris: Klincksieck, s. 131-173.

DeMAROLle P., 1986: A propos d'un «Traitiet moult profitable» : la place de la notion de phrase en syntaxe descriptive, w: Actes $d u$ XVIIIe Congrès International de Linguistique et Philologie Romane, mai 1986, t. I, TRIER, s. 43-52.

KĘSIK M., 1989: La cataphore, Paris: PUF.

KLEIBER G., 2001: L'anaphore associative, Paris: PUF.

LEMIEUX M., MARCHELLO-NIZIA Ch., 1997: L'analyse quantitative en diachronie, w: Le Moyen Français. Philologie et linguistique. Approches du texte et du discours. Actes du VIIle Colloque International sur le moyen français, red. B. Combettes, S. Monsonégo, Didier-Paris, s. 530-571.

MAILlARD M., 1974: Essai de typologie des substituts diaphoriques (Supports d'une anaphore et/ou d'une cataphore), "Langue française” no 21, s. 55-71.

MiLNER J.-C., 1982: Ordres et raisons de langue, Paris-Seuil. 


\section{Les instruments de la cohésion dans « le Livre des fais et bonnes meurs du sage roy Charles $\mathrm{V}$ » de l'écrivaine médiévale Christine de Pizan}

\section{(résumé)}

Cet article est une tentative pour vérifier si la méthodologie moderne de la cohésion textuelle, est pertinente dans le texte de Christine de Pizan où les relations cohésives dépendent de différents facteurs. Puisque les expressions diaphoriques sont un moyen de maintenir et assurer la cohérence du texte d'une façon économique, l'observation de ces facteurs dans le texte médiéval en prose de Christine montre à quel point la diaphore est un phénomène discursif riche et complexe. Le concept d'économie du texte laquelle n'est qu'une moyenne des règles linguistiques et les éléments qui assurent la progression du texte ne constituent qu'un aspect de ce procédé. Dans l'univers textuel, la progression thématique n'est pas toujours «logique» du point de vue de l'orientation informative; il arrive que des constructions, à première vue diaphoriques, qui ne les soient pas dans la saisie globale du texte, parce qu'elles reprennent une information présentée auparavant, sans continuité informationnelle maintenue par d'autres instruments cohésifs. De plus, la structure compilative des œuvres en prose de Christine fait créer «un univers dans l'univers textuel», ouvrant une voie à des liens cohésifs inattendus. 